\title{
A new approach to establish safe levels of available metals in soil with respect to potential health hazard of human
}

\author{
Debasis Golui $^{1}$ - S. P. Datta ${ }^{1}$ - B. S. Dwivedi ${ }^{1}$ - M. C. Meena ${ }^{1}$ - P. Ray ${ }^{1} \cdot$ V. K. Trivedi $^{1}$
}

Received: 30 March 2021 / Accepted: 16 September 2021 / Published online: 25 September 2021

(c) The Author(s), under exclusive licence to Springer-Verlag GmbH Germany, part of Springer Nature 2021

\begin{abstract}
Safe levels of extractable pollutant elements in soil have not been universally established. Prediction of metal solubility in polluted soils and the subsequent transfer of these metals from soil pore water to the human food supply via crops are required for effective risk assessment from polluted soils. Thus an attempt has been made to develop a novel approach to protect human health from exposure to toxic metals through assessing risk from metal polluted soils utilised for agriculture. In this study, we assess the relative efficacy of various forms of 'free ion activity model' (FIAM) for predicting the concentration of cadmium $(\mathrm{Cd})$, lead $(\mathrm{Pb})$, nickel $(\mathrm{Ni})$, zinc $(\mathrm{Zn})$ and copper $(\mathrm{Cu})$ in spinach and wheat as example crops, thereby providing an assessment of risk to human health from consumption of these crops. Free metal ion activity in soil solution was estimated using the Windermere Humic Aqueous Model VII (WHAM-VII) and the Baker soil test. Approximately 91, 81, 75,94 and $70 \%$ of the variability in $\mathrm{Cd}, \mathrm{Pb}, \mathrm{Ni}, \mathrm{Zn}$ and $\mathrm{Cu}$ content, respectively, of spinach could be described by a FIAM using an estimate of the free ion activity of the metals provided by WHAM-VII. Owing to the different concentration of ethylenediamine tetraacetic acid (EDTA) and diethylenetriamine pentaacetic acid (DTPA) used in the present experiment, higher prediction coefficients were obtained using EDTA $(0.05 \mathrm{M})$, rather than DTPA $(0.005 \mathrm{M})$, as the metal extractant in an integrated solubility-FIAM model. Out of three formulations, the FIAM, based on free ion activity of metals in soil pore water, determined from solution extracted with Rhizon samplers, was distinctly superior to the other formulations in predicting metal uptake by spinach and wheat. A safe level of extractable metal in soil was prescribed using a hazard quotient derived from predicted plant metal content and estimated dietary intake of wheat and spinach by a human population.
\end{abstract}

Keywords Polluted soil $\cdot$ Metal $\cdot$ Free ion activity model (FIAM) $\cdot$ Risk assessment $\cdot$ Hazard quotient (HQ) $\cdot$ Safe limit

\section{Introduction}

Use of waste waters (industrial effluents and domestic sewage) for irrigating crop lands is expanding steadily owing to the paucity of fresh water reserves (Golui et al. 2020). The presence of substantial amounts of essential plant nutrients in waste water may enhance the agricultural productivity (Chen et al. 2005). Application of sewage effluents has been reported to improve soil chemical and physical characteristics including organic carbon as well as major and micronutrients (Meena et al. 2016). Besides, enrichment of the edible portions of rice and wheat has also been

\footnotetext{
S. P. Datta

profssac2017@gmail.com

1 Division of Soil Science and Agricultural Chemistry, ICARIndian Agricultural Research Institute (ICAR-IARI), Pusa Campus, New Delhi 110012, India
}

reported due to irrigation with sewage (Meena et al. 2016). Conversely, the application of such effluents on farming land frequently results in build-up of toxic metals in soils in the long term (Rattan et al. 2005; Deshmukh et al. 2015; Meena et al. 2016). It has been established beyond doubt that crops grown on such metal-loaded soils may surpass the legislative limits for toxic metals in the palatable portions of crops (Nabulo et al. 2011). Excessive intake of metals through the human diet may lead to several health complications. For example, excess cadmium (Cd) may result in aminoaciduria, namely itai-itai disease. Encephalopathy, failure in reproduction and metabolic disorders have been associated with lead toxicity in humans. Zinc toxicity may lead to a reduction in the functioning of $\mathrm{Fe}$ in human, thereby causing anaemia (Rattan et al. 2009). Nickel and $\mathrm{Cu}$ are tumourdeveloping agents, whose mutagenic effect has attracted worldwide concerns. Exposure to nickel-enriched dust may induce nasopharyngeal carcinoma in humans (Chen 2011). 
Therefore, an assessment of the suitability of agricultural land for crop production in respect of its metal status should be an integral part of preventing food-chain contamination. Over the years, total soil metal content has been used as the simplest index of metal hazard, but this does not take into consideration the effect of soil properties on metal solubility and bioavailability. Hence, such indices are not always meaningful in either protecting human health from metal hazards or judging the suitability of agricultural lands for crop production. Use of too stringent permissible limits is not desirable, considering the current continuing loss of agricultural land. Furthermore, such permissible limits should also be crop-specific.

The free ion activity in the soil pore water, described as an 'intensity factor', is a key indicator of metal-related risk in terms of leaching and bioavailability (Oorts et al. 2006). Most studies suggest that measurement of 'intensity' of metals in soil is preferred to the determination of metal 'quantity factors' for prediction of bioavailability of metals and associated risk (Datta and Young 2005; Meena et al. 2016; Golui et al. 2017; Mandal et al. 2019). Thus the intensity of metal in pore water has a direct effect on the metal bioavailability to crops and ecotoxicity to microbial communities (Vulkan et al. 2000; Groenenberg et al. 2010). One way of measuring the intensity of metal in soils is in-situ withdrawal of soil pore water through Rhizon sampler from the root zone of growing crops, followed by speciation using geochemical models such as WHAM VII (Tipping et al. 2011; Marzouk et al. 2013; Mao et al. 2017; Mishra et al. 2019). Free ion activity may be estimated by the simple Baker soil test programme of Baker and Amacher (1981). Empirical and semiempirical procedures have also been applied to replace more tedious soil solution extraction and speciation procedures (Hough et al. 2003; Tye et al. 2003; Datta and Young 2005). Recently, the efficacy of the simpler approaches (Baker soil test, empirical and semi empirical) for determining free metal ion activity in soil solution was evaluated against the more direct technique utilizing Rhizon sampler for extraction of soil solution and following speciation by WHAM VII model (Golui et al. 2020). However, the usefulness of these approaches have not been evaluated as predictors of plant metal uptake.

Precise prediction of plant uptake of metal is of supreme consequence for prescribing the permissible limit of metals in soil in respect of the knowledge of the dietary uptake of metals via ingestion of foodstuff cultivated on metal polluted soils. In this regard, there is limited information on the application of free ion activity models (FIAM) for predicting transport of metal from soil to crop, particularly in tropical soils with low organic carbon content. The FIAM for prediction of transfer of metal to plant was conceptualized in the early 1980's and has been adapted following the principles of the biotic ligand model (Campbell 1995; Datta and Young 2005). The FIAM is conceptually built on the interchange and binding of free metal ions with the cellular binding sites on plant roots built on a common chemical equilibrium theory. Several formulations of the FIAM have been implemented using both measured free ion activity $\left(\mathrm{M}^{2+}\right)$ and modelled $\left(\mathrm{M}^{2+}\right)$ data (Hough et al. 2004; Datta and Young 2005). In an extended procedure, uptake of metal by plants can be predicted reasonably well using an integrated solubility and FIAM approach, based on the predicted ion activity of metal in the soil solution (Hough et al. 2003, 2004; Golui et al. 2017).

Plant metal content as predicted by the most accurate free ion activity model could be used for assessing risk from dietary metal intake by humans and thereby prescribing permissible limits for metal concentrations in soil. The present study attempted to develop a comprehensive tool for risk assessment of polluted soil. Objectives of the present study are 1) assessing the relative efficacy of several formulations of the FIAM for predicting the transport of zinc, copper, nickel, lead and cadmium using spinach and wheat as test crops, (2) to develop risk assessment protocols for polluted soil pertaining to health hazard of human, and (3) to prescribe safe limits of extractable metals in soil.

\section{Materials and methods}

Contaminated soil samples (25) in bulk were brought from various sites (Fig. 1 and Table S1). Four soil samples in bulk were also brought from nearby agricultural sites which did not have the history of receiving industrial effluents or solid waste.

\section{Analysis of soil for chemical properties}

After processing (air-drying followed by sieving with 2-mm sieve), samples were analysed for important chemical properties. Samples were analysed in triplicate for $\mathrm{pH}$, organic carbon and texture following the protocol of Jackson (1973), Walkley and Black (1934) and Bouyoucos (1962), respectively.

\section{Concentrations of zinc, copper, nickel, lead and cadmium}

Total concentrations of zinc, copper, nickel, lead and cadmium were measured in inductively coupled plasma-mass spectrometry (ICP-MS) (Perkin Elmer NexIon 300) following digestion with mixture of $\mathrm{HNO}_{3}$ and $\mathrm{HCl} @ 1: 3$ (Quevauviller, 1998). Concentrations of metals extractable with EDTA (0.05 M) and DTPA $(0.005 \mathrm{M})$ solution were also measured by ICP-MS following the protocol of Quevauviller (1998) and Lindsay and Norvell (1978), respectively. 


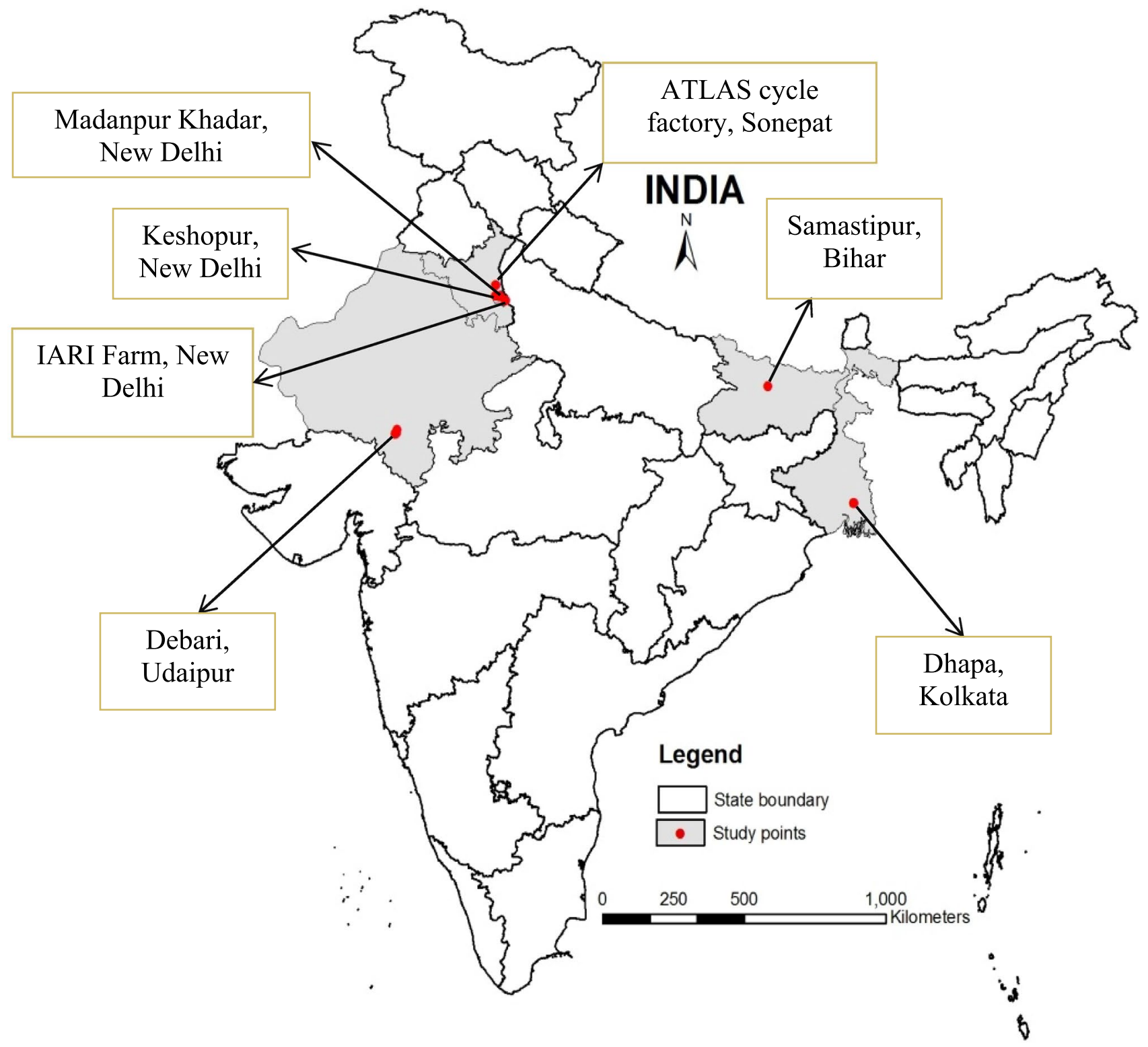

Fig. 1 Map showing the locations of the contaminated soils used in this study

\section{Greenhouse pot experiment}

An experiment was carried out in greenhouse, using processed soil from each location, with spinach and wheat (details in supplementary information, section A1).

\section{Soil solution extraction, analysis and speciation}

\section{Rhizon samplers}

Soil pore water was collected from the pot experiment using Rhizon samplers. Prior to sampling of soil solution, pots were irrigated. After draining of excess moisture, soil solution was collected in situ according to Golui et al. (2020). A portion of the filtered soil solution was used for analysis of $\mathrm{Na}, \mathrm{Mg}, \mathrm{K}, \mathrm{Ca}, \mathrm{Zn}, \mathrm{Cu}, \mathrm{Fe}, \mathrm{Mn}, \mathrm{Ni}, \mathrm{Pb}, \mathrm{Cd}$; the remainder was used for determination of $\mathrm{Cl}, \mathrm{NO}_{3}, \mathrm{SO}_{4}$, $\mathrm{PO}_{4}$, dissolved organic- and inorganic carbon as reported by Golui et al. (2020). Speciation analysis was carried out using WHAM-VII for determination of the free metal ion activity following Tipping et al. (2011).

\section{Baker soil test}

The free metal ion activities in soils were also estimated following the standard procedure described by Baker and 
Amacher (1981) (details in supplementary information, section A2).

\section{Prediction of plant metal uptake}

The following forms of the FIAM were used to predict the metal uptake by spinach and wheat.

\section{Model I (EDTA \& DTPA): Integrated solubility-FIAM}

An 'integrated solubility-FIAM' was used for prediction of metal uptake by spinach and wheat grain. The FIAM suggests that metal uptake by plant is governed by metal ion activity in soil solution. A transfer factor (TF) is given as the ratio of $\left[M_{\text {plant }}\right]$ to $\left(M^{2+}\right)$ (Eq. 1).

$\mathrm{TF}=\frac{\left[M_{\text {Plant }}\right]}{\left(M^{2+}\right)}$,

where $\left[M_{\text {plant }}\right]$ is the plant metal content; $\left(M^{2+}\right)$ is free metal ion activity.

The free ion activity of metal $\left(\mathrm{M}^{2+}\right)$ was predicted from a $\mathrm{pH}$-dependent Freundlich equation according to Golui et al. (2020). Metal uptake by spinach and wheat can be predicted by combining Eq. (1) with $\left(\mathrm{M}^{2+}\right)$ as follows:

$\log \left[M_{\text {plant }}\right]=C+\beta_{1} \mathrm{pH}+\beta_{2} \log \left[M_{\mathrm{c}}\right]$,

where $C, \beta_{1}$ and $\beta_{2}$ are empirical metal and plant-specific coefficients. The 'Solver' facility in Microsoft Excel 2020 was used to parameterize Eq. (2) through non-linear error minimization. For calculation of error sum of squares, numerical data on plant metal content were used rather than logarithmic data.

\section{Model II (Rhizon): FIAM depended on metal ion activity in soil pore water as estimated through geochemical speciation model}

Prediction of plant metal content was made using a biotic ligand model (BLM) formulation. The underlying principle of this approach is that metal sorption (1) occurs on assumed root surface and (2) is in competition with positive ions $\left(\mathrm{H}^{+}\right.$ and cations) for the root surface. Total root surface can be given as:

$R_{\mathrm{T}}=\mathrm{RM}+\mathrm{RH}+R$

$R_{\mathrm{T}}=$ total root surface; $\mathrm{RM}=$ Metal absorbed sites; $\mathrm{RH}=H^{+}$absorbed sites; $R=$ Free sites. The procedure of absorption of metal and $H^{+}$can be given as Eqs. 4 and 5:
$M^{2+}+R \rightleftarrows \mathrm{RM} ; K_{\mathrm{M}}=\frac{\mathrm{RM}}{\left(\mathrm{M}^{2+}\right) R}$

$H^{+}+R \rightleftharpoons \mathrm{RH} ; K_{\mathrm{H}}=\frac{\mathrm{RH}}{\left(H^{+}\right) R}$

$K_{\mathrm{M}}$ and $K_{\mathrm{H}}$ do not consider possible effects of variation in $\mathrm{pH}$ or positive ion absorption on root membrane properties. Adding Eqs. 3-5 and assuming that metal uptake by spinach /wheat grain, namely $\left[M_{\text {spinach/wheat }}\right]$, is proportional to RM, leads to Eq. (6).

$M_{\text {spinach/wheat }}=\frac{K_{\mathrm{t}} R_{\mathrm{T}} K_{\mathrm{M}}\left(M^{2+}\right)}{1+K_{\mathrm{M}}\left(M^{2+}\right)+K_{\mathrm{H}}\left(H^{+}\right)}$,

where $K_{\mathrm{t}}$ is a proportionality constant presuming that the content of metal ions on root sorption sites during the entire growth period of crop is reflected by the concentration of metal in the shoot and grain of the plant. Parameterization of model equation (Eq. 6) was done in 'Solver' in MS Excel 2020 .

\section{Model III (Baker): FIAM depended on metal ion activity in soil pore water as estimated through Baker soil test programme}

For Model III, the formulation of the FIAM was identical to Model II except that the free ion activity of metal $\left(\mathrm{M}^{2+}\right)$ in soil pore water was estimated using the Baker soil test programme.

\section{Risk assessment}

Hazard quotients (HQ) were computed following US-EPA protocols (IRIS 2020) to appraise health hazard of human due to dietary ingestion of metals through spinach and wheat grain grown on polluted soils.

$\mathrm{HQ}=\frac{\mathrm{ADD}}{R_{\mathrm{f}} D}$,

where ADD is average daily dose $\left(\mathrm{mg} \mathrm{kg}^{-1} \mathrm{day}^{-1}\right)$ and $\mathrm{R}_{\mathrm{f}} \mathrm{D}$ is reference dose $\left(\mathrm{mg} \mathrm{kg}^{-1} \mathrm{day}^{-1}\right)$ of metals. The $R_{\mathrm{f}} D$ values are 0.3 for $\mathrm{Zn}, 0.5$ for $\mathrm{Cu}, 0.02$ for $\mathrm{Ni}, 0.0035$ for $\mathrm{Pb}$ and 0.001 for Cd (IRIS 2020; WHO 1982). Recommended dietary consumption of spinach of $0.2 \mathrm{~kg} \mathrm{day}^{-1}$ (fresh weight) was considered for computation of $\mathrm{HQ}$, while in case of wheat it is $0.4 \mathrm{~kg} \mathrm{day}^{-1}$. The HQ for metal intake with the consumption of spinach and wheat was calculated according to Eq. (8) for an adult (average body weight is $70 \mathrm{~kg}$ ). 
$\mathrm{HQ}=\frac{M_{\text {plant }} \times W \times F}{R_{\mathrm{f}} D \times 70}$,

where $M_{\text {plant }}$ is the concentration of metal in spinach and wheat; $W$ is the consumption of vegetables and wheat $(\mathrm{kg})$; $F$ is the conversion factor i.e. 0.082 for spinach and 1 for wheat.

Values of hazard quotient up to unity are considered as safe, when all probable routes of entry of metal to human body are calculated i.e. a complete risk assessment. But in the present case, assessment of risk is not complete, since metal intake by humans can occur by other possible routes as well. Hence, Meena et al. (2016) proposed a safe limit of $\mathrm{HQ}$ for rice and wheat as 0.5 . Owing to the fact that dietary intake of green vegetable by human being is far less than staple food like rice or wheat, a safe limit of HQ for green vegetable is proposed here as 0.25 . Hence, critical values of $\mathrm{HQ}$ in case of spinach and wheat were considered as 0.25 and 0.50 , respectively for ascertaining the permissible level of available metal at a certain organic carbon and soil $\mathrm{pH}$ under modelling framework. The reason behind fixation of relatively lower critical value of $\mathrm{HQ}$ for spinach is based on the presumption that a small amount of the daily human diet is constituted by green vegetables.

\section{Results and discussion}

\section{Physiochemical properties}

The mean value of soil $\mathrm{pH}$ was $7.61 \pm 0.31$; the extent of soil $\mathrm{pH}$ in the twenty nine experimental soils varied from neutral to alkaline (Table S2). The mean soil organic carbon content was $1.12 \pm 0.24 \%$; the Dhapa soil had the highest value $(2.68 \pm 0.40 \%)$, where solid wastes of municipalities have been deposited for the last forty years. High organic matter contents may be associated with long-term application of municipal solid wastes, sewage-sludge, and industrial effluents. The mean clay content was $22.5 \pm 6.71 \%$. The soils covered six textural classes: silty clay loam, clay, clay loam, sandy loam, loam, and sandy clay loam.

\section{Total and extractable metals}

The range of total metal concentration across the studied soils were 28.2-28,662, 23.6-2305, 11.4-1513, 7.90-3793 and $0.22-352 \mathrm{mg} \mathrm{kg}^{-1}$ for $\mathrm{Zn}, \mathrm{Cu}, \mathrm{Ni}, \mathrm{Pb}$ and $\mathrm{Cd}$, respectively with the corresponding median value of 381,226 , 25.6, 22.2 and $2.13 \mathrm{mg} \mathrm{kg}^{-1}$ (Table S3). An apparent elevation of $\mathrm{Cd}, \mathrm{Pb}$ and $\mathrm{Zn}$ in Debari soils may have resulted from the application of $\mathrm{Zn}$-smelter effluents from smelter plants on a long-term basis. The Dhapa site receiving municipal solid was located adjacent to Kolkata city roads with high traffic volumes and exhibited the highest level of $\mathrm{Pb}$, thereby (probably) reflecting emissions from automobiles (USEPA 2017). The total Ni content was higher in the soils of Sonepat, reflecting irrigation using cycle industry effluents where $\mathrm{Ni}$ is included in the production of stainless steel (Cempel and Nikel 2006). Sewage irrigated soils of Keshopur and river water irrigated soils of Madanpur showed relatively higher values of $\mathrm{Ni}$ and $\mathrm{Cu}$. Generally, contaminated sites treated with effluents from various industries and solid waste showed higher levels of all metals compared to soils treated with polluted river water and sewage.

The range of $\mathrm{Zn}, \mathrm{Cu}, \mathrm{Ni}, \mathrm{Pb}$ and $\mathrm{Cd}$ as extracted with EDTA were 1.98-13,784, 1.89-1535, 2.28-303, 1.98-625 and $0.09-246 \mathrm{mg} \mathrm{kg}^{-1}$, respectively with the corresponding median value of $102,78.4,7.25,12.3$ and $0.87 \mathrm{mg} \mathrm{kg}^{-1}$ (Table S3) whereas the range of DTPA extractable metal concentrations across the studied soils were $0.45-755$, $0.18-210,0.07-15.3,0.65-92.8,0.01-77.4 \mathrm{mg} \mathrm{kg}^{-1}$ for $\mathrm{Zn}, \mathrm{Cu}, \mathrm{Ni}, \mathrm{Pb}$ and $\mathrm{Cd}$, respectively with the corresponding median value of $32.7,4.93,0.86,4.93,0.21 \mathrm{mg} \mathrm{kg}^{-1}$ (Table S4). The concentrations of extractable metals were used as indicator of the labile pool of metal for prediction of metal uptake by plants using Model I.

\section{Free metal ion activity in soil pore water}

The Baker extracts showed significantly higher concentrations of all metals $\left(5.57,2.38,0.33,0.73\right.$ and $0.41 \mathrm{mg} \mathrm{L}^{-1}$ for $\mathrm{Zn}, \mathrm{Cu}, \mathrm{Ni}, \mathrm{Pb}$ and $\mathrm{Cd}$, respectively) compared to the Rhizon extracts (Table S5). Soil solution extracted through in-situ Rhizon samplers directly represents the pore water of the root zone. Whereas, the Baker extracts use DTPA for soil extraction to estimate free metal ion activity in soil pore water. The mean free metal ion activities in soil pore water extracted from the rhizosphere of spinach using Rhizon samplers, and estimated using WHAM VII, were $6.93 \pm 0.32$ for $\mathrm{pZn}^{2+}, 10.1 \pm 0.68$ for $\mathrm{pCu}^{2+}, 7.70 \pm 0.28$ for $\mathrm{pNi}^{2+}, 10.3 \pm 0.32$ for $\mathrm{pPb}^{2+}$ and $9.08 \pm 0.45$ for $\mathrm{pCd}^{2+}$ (Table S6). Corresponding values under wheat rhizospheres were $7.03 \pm 0.38,10.2 \pm 0.59,7.65 \pm 0.31,10.7 \pm 0.42$ and $9.28 \pm 0.54$, respectively (Table S7). The Baker soil test also provided similar location-specific changes in free metal ion activities. The average free metal ion activities as estimated with the Baker soil test programme were $10.1 \pm 1.12$ for $\mathrm{pZn}^{2+}, 13.4 \pm 1.23$ for $\mathrm{pCu}^{2+}, 12.9 \pm 0.85$ for $\mathrm{pNi}^{2+}$, $11.6 \pm 0.74$ for $\mathrm{pPb}^{2+}$ and $12.6 \pm 2.26$ for $\mathrm{pCd}^{2+}$ (Table S8).

\section{Prediction of metal uptake by crops}

Total metal concentration in spinach and wheat varied considerably among the experimental soils. In edible portion of spinach, metal concentration ranged from 57.2 to 
$1245 \mathrm{mg} \mathrm{kg}^{-1}$ for $\mathrm{Zn}, 3.85$ to $40.2 \mathrm{mg} \mathrm{kg}^{-1}$ for $\mathrm{Cu}, 0.55$ to $15.5 \mathrm{mg} \mathrm{kg}^{-1}$ for $\mathrm{Ni}, 0.40$ to $82.0 \mathrm{mg} \mathrm{kg}^{-1}$ for $\mathrm{Pb}$ and 0.15 to $48.3 \mathrm{mg} \mathrm{kg}^{-1}$ for Cd (Table S9). The corresponding median values were $164,8.31,1.04,1.93$ and $0.48 \mathrm{mg} \mathrm{kg}^{-1}$ for $\mathrm{Zn}$, $\mathrm{Cu}, \mathrm{Ni}, \mathrm{Pb}$ and $\mathrm{Cd}$, respectively. By contrast, total metal concentrations in wheat grain varied from 12.6 to $98.5 \mathrm{mg} \mathrm{kg}^{-1}$ for $\mathrm{Zn}, 1.53$ to $10.3 \mathrm{mg} \mathrm{kg}^{-1}$ for $\mathrm{Cu}, 0.18$ to $2.80 \mathrm{mg} \mathrm{kg}^{-1}$ for $\mathrm{Ni}, 0.08$ to $0.74 \mathrm{mg} \mathrm{kg}^{-1}$ for $\mathrm{Pb}$ and 0.02 to $10.4 \mathrm{mg} \mathrm{kg}^{-1}$ for $\mathrm{Cd}$. The median values of metal concentrations in wheat grain were $54.5,5.26,0.38,0.21$ and $0.17 \mathrm{mg} \mathrm{kg}^{-1}$ for $\mathrm{Zn}$, $\mathrm{Cu}, \mathrm{Ni}, \mathrm{Pb}$ and $\mathrm{Cd}$, respectively. Metal concentrations in dicotyledonous spinach (high root CEC) were considerably higher than in monocotyledonous wheat grain (low root CEC). Higher rates of transpiration in spinach lead to greater absorption of metals by plants (Zhou et al. 2016). These two contrasting crops in respect of metal uptake efficiency and dietary intake by human were used as test crops to ensure wider applicability of permissible limits.

\section{Model-I (EDTA and DTPA)}

The prediction coefficients $\left(R^{2}\right)$ and model parameters $\left(C, \beta_{1}\right.$ and $\beta_{2}$ ) of the integrated solubility and free ion activity model (Model I) are presented in Table 1. It has been found that 78, 57, 64, 67 and $93 \%$ of the change in $\mathrm{Zn}, \mathrm{Cu}, \mathrm{Ni}, \mathrm{Pb}$ and $\mathrm{Cd}$ concentrations of spinach, respectively, could be described by soil reaction and $\mathrm{M}_{\mathrm{C}}$ (labile pool of metals assumed to be adsorbed on organic matter as extracted by EDTA) (Figure S1). By contrast, the prediction coefficients of the model as obtained for $\mathrm{Zn}$, $\mathrm{Cu}, \mathrm{Ni}, \mathrm{Pb}$ and $\mathrm{Cd}$ were $0.51,0.55,0.63,0.66$ and 0.87 , respectively using labile pool of metals as extracted with DTPA (Figure S2). The Model I (EDTA) based on EDTA extractable metal could describe the changes in metal concentration in wheat grain to the extent of $53 \%$ for $\mathrm{Zn}, 42 \%$ for $\mathrm{Cu}, 85 \%$ for $\mathrm{Ni}, 52 \%$ for $\mathrm{Pb}$ and $88 \%$ for $\mathrm{Cd}$ (Table 1 ).
Prediction coefficients of 0.71 for $\mathrm{Zn}, 0.19$ for $\mathrm{Cu}, 0.81$ for $\mathrm{Ni}, 0.45$ for $\mathrm{Pb}$ and 0.87 for $\mathrm{Cd}$ were obtained for wheat grain in Model I (DTPA). This model involves determination of soil characteristics like soil reaction, soil organic carbon and available metals. Meena et al. (2016) reported that organic carbon and $\mathrm{pH}$ are among the key soil chemical characteristics which govern the metal solubility in polluted soils. Considerable variation in the crop and the metal-specific constants indicated the uniqueness of model parameters for each metal and crop. Values of $\beta_{2}$ in Model I were positive for all metals in both the crops. Thus, as expected, elevated concentrations of available metals in experimental soil will magnify the concentration of studied metals in the edible portion of spinach and wheat. In Model I, the free ion activity of metal in soil solution was predicted through Freundlich equation (solubility model). Hence, it is likely that the use of a more directly estimated free metal ion activity would enhance the predictive power of this formulation of the FIAM, as presented in the following section of the paper. However, values of prediction coefficients $\left(\mathrm{R}^{2}\right)$ were more than 0.5 in all cases. Overall, for both crops, the use of EDTA-extractable metal concentration in the model yielded higher prediction coefficients compared to the DTPA-extractable metals. This may be due to the higher efficiency of EDTA in extracting metals from highly polluted soils due to the higher concentration of the extractant (ten times) in comparison to DTPA (0.005 M). The DTPA extractant may be capacity limited and may not reflect the full labile metal pool in soils with a large available metal concentration. Findings of the present research work is in concurrence with the findings of (Zan et al. 2013), where it was reported that prediction of free ion activity by solubility model ( $\mathrm{pH}$ dependent Freundlich equation) based on EDTA-extractable metal yielded higher prediction coefficient in comparison to model based on labile pool of metal as extracted with DTPA.

Table 1 Model parameters for predicting uptake of $\mathrm{Zn}, \mathrm{Cu}, \mathrm{Ni}, \mathrm{Cd}$ and $\mathrm{Pb}$ by spinach and wheat as a function of $\mathrm{pH}$, soil organic carbon content and extractable metals (Model I-EDTA and DTPA)

\begin{tabular}{|c|c|c|c|c|c|c|c|c|c|c|c|c|c|c|c|c|}
\hline \multirow[t]{4}{*}{ Metal } & \multicolumn{8}{|c|}{ Spinach } & \multicolumn{8}{|l|}{ Wheat } \\
\hline & \multicolumn{4}{|l|}{ EDTA } & \multicolumn{4}{|l|}{ DTPA } & \multicolumn{4}{|l|}{ EDTA } & \multicolumn{4}{|l|}{ DTPA } \\
\hline & \multicolumn{3}{|c|}{ Model parameters } & \multirow[t]{2}{*}{$R^{2}$} & \multicolumn{3}{|c|}{ Model parameters } & \multirow[t]{2}{*}{$R^{2}$} & \multicolumn{3}{|c|}{ Model parameters } & \multirow[t]{2}{*}{$R^{2}$} & \multicolumn{3}{|c|}{ Model parameters } & \multirow[t]{2}{*}{$\mathrm{R}^{2}$} \\
\hline & $C$ & $\beta_{1}$ & $\beta_{2}$ & & $C$ & $\beta_{1}$ & $\beta_{2}$ & & $C$ & $\beta_{1}$ & $\beta_{2}$ & & C & $\beta_{1}$ & $\beta_{2}$ & \\
\hline $\mathrm{Zn}$ & -2.84 & 0.11 & 0.36 & 0.78 & -2.81 & 0.06 & 0.41 & 0.51 & -2.34 & 0.04 & 0.23 & 0.53 & -2.35 & 0.06 & 0.16 & 0.71 \\
\hline $\mathrm{Cu}$ & -2.79 & 0.20 & 0.19 & 0.57 & -2.56 & 0.12 & 0.30 & 0.55 & -1.07 & 0.02 & 0.09 & 0.42 & -1.16 & 0.05 & 0.04 & 0.19 \\
\hline $\mathrm{Ni}$ & -3.65 & 0.32 & 0.52 & 0.64 & -2.94 & 0.13 & 0.61 & 0.63 & -1.36 & -0.005 & 0.59 & 0.85 & -1.98 & 0.17 & 0.48 & 0.81 \\
\hline $\mathrm{Pb}$ & -3.31 & 0.22 & 0.59 & 0.67 & -4.05 & 0.15 & 0.93 & 0.66 & 0.15 & 0.03 & 0.12 & 0.52 & 0.14 & 0.05 & 0.07 & 0.45 \\
\hline $\mathrm{Cd}$ & -3.62 & 0.20 & 0.72 & 0.93 & -3.17 & 0.06 & 0.78 & 0.87 & -3.72 & 0.25 & 0.70 & 0.88 & -2.87 & 0.22 & 0.56 & 0.87 \\
\hline
\end{tabular}

The values of $R^{2}>0.18$ are significant at $5 \%$ probability level 


\section{Model II (Rhizon) and III (Baker)}

The present study attempted to predict the metal uptake by plant using FIAM based on estimated free ion activity of metal in soil solution (WHAM VII and Baker soil test extract). The $\mathrm{R}^{2}$ values of model II (Rhizon) and model III (Baker) for different metals are presented in Table 2. The FIAM based on free metal ion in soil solution, as speciated by WHAM VII, was able to capture the changes in metal concentration of spinach to the level of 94, 70, 75, 81 and $91 \%$ for $\mathrm{Zn}, \mathrm{Cu}, \mathrm{Ni}, \mathrm{Pb}$ and $\mathrm{Cd}$, respectively (Figure S3). Free ion activity accounted for variations in metal concentration of spinach to tune of $76 \%$ for $\mathrm{Zn}, 62 \%$ for $\mathrm{Cu}, 60 \%$ for $\mathrm{Ni}, 41 \%$ for $\mathrm{Pb}$ and $71 \%$ for $\mathrm{Cd}$, when free metal ion activity, as speciated by Baker soil test, was used as an input for FIAM (Table 2 and Figure S4). As high as $70,61,85,75$ and $88 \%$ changes in $\mathrm{Zn}, \mathrm{Cu}, \mathrm{Ni}, \mathrm{Pb}$ and $\mathrm{Cd}$ concentration in wheat grain, respectively, could be captured by this model, considering free metal ion in soil solution (Rhizon-WHAM VII) (Table 2). Prediction coefficients of 0.51 for $\mathrm{Zn}, 0.22$ for $\mathrm{Cu}, 0.50$ for $\mathrm{Ni}, 0.31$ for $\mathrm{Pb}$ and 0.75 for $\mathrm{Cd}$ were obtained, when free ion activity of metal in soil solution, as estimated by Baker soil test, was used as model input. Generally, in both the crops and for all the metals, there was a closer agreement between the measured and the predicted values of metal uptake by plant, when FIAM was based on Rhizon-WHAM VII as compared to that of Baker soil test. The main distinction between these speciation techniques lies in the extraction of soil solution and in further speciation. In the case of WHAM VII, in-situ withdrawal of soil solution is done with the help of Rhizon sampler, whereas in case of Baker soil test ex-situ extraction of soil sample is done using the DTPA extractant. Hence, the composition of Rhizon sampler extracted soil solution is expected to be closer to that of the pore water as compared to that of Baker soil test. Further, WHAM VII is a robust ion speciation model based on a large experimental data set, whereas the Baker test algorithm is based on more limited data and requires that soil is extracted with a chelating agent and salt solution. On the other hand, in theory, Rhizon samplers extract the soil solution which is actually bathing the surface of the plant roots and therefore provides a more realistic measure of metal ion intensity.

The relative efficacy of different formulations of FIAM in predicting uptake of metal by spinach and wheat was compared in terms of the mean prediction coefficient (Table S10). The highest mean prediction coefficient $\left(R^{2}=0.82\right)$ for uptake of metals by spinach was recorded for Model II (Rhizon) based on the integrated use of RhizonWHAM VII. On the other hand, Model III (Baker), based on Baker soil test data was less effective in predicting uptake of metals by spinach (mean $R^{2}=0.62$ ). Model I, based on EDTA-extractable metal yielded a higher mean prediction coefficient (mean $R^{2}=0.72$ ) in comparison to the use of DTPA-extractable metal (mean $R^{2}=0.64$ ). The efficacy of different formulations of FIAM for predicting metal uptake by plants follows the order of Model II (Rhizon) > Model I $($ EDTA $)>$ Model I (DTPA) $>$ Model III (Baker).

\section{Protocol and prescription of permissible limits}

\section{Risk assessment}

The value of HQ below 1 for complete risk assessment, i.e. where HQ is based on total metal intake from various exposure paths (food materials, drinking water ingestion of soil and inhalation of dust) has been considered safe as per USEPA. However, in the present study a partial

Table 2 Model parameters for predicting uptake of $\mathrm{Zn}, \mathrm{Cu}, \mathrm{Ni}, \mathrm{Pb}$ and $\mathrm{Cd}$ by spinach and wheat as a function of estimated free metal ion activity $\left(M^{2+}\right)$ and soil $\mathrm{pH}$

\begin{tabular}{|c|c|c|c|c|c|c|c|c|c|c|c|c|c|c|c|c|}
\hline \multirow[t]{4}{*}{ Metal } & \multicolumn{8}{|l|}{ Spinach } & \multicolumn{8}{|l|}{ Wheat } \\
\hline & \multicolumn{4}{|c|}{$\begin{array}{l}\text { Estimated free metal ion } \\
\text { activity }^{\mathrm{a}}\end{array}$} & \multicolumn{4}{|c|}{$\begin{array}{l}\text { Estimated free metal ion } \\
\text { activity }{ }^{\mathrm{b}}\end{array}$} & \multicolumn{4}{|c|}{ Estimated free metal ion activity } & \multicolumn{4}{|c|}{$\begin{array}{l}\text { Estimated free metal ion } \\
\text { activity }^{\mathrm{b}}\end{array}$} \\
\hline & \multicolumn{3}{|c|}{ Model parameters } & \multirow[t]{2}{*}{$R^{2}$} & \multicolumn{3}{|c|}{ Model parameters } & \multirow[t]{2}{*}{$R^{2}$} & \multicolumn{3}{|c|}{ Model parameters } & \multirow[t]{2}{*}{$\mathrm{R}^{2}$} & \multicolumn{3}{|c|}{ Model parameters } & \multirow[t]{2}{*}{$R^{2}$} \\
\hline & $K_{\mathrm{M}}{ }^{\mathrm{a}} \mathrm{NS}$ & $K_{\mathrm{H}}$ & $K_{\mathrm{M}}$ & & $K_{\mathrm{M}}{ }^{\mathrm{a}} \mathrm{NS}$ & $K_{\mathrm{H}}$ & $K_{\mathrm{M}}$ & & $K_{\mathrm{M}}{ }^{\mathrm{a}} \mathrm{NS}$ & $K_{\mathrm{H}}$ & $K_{\mathrm{M}}$ & & $K_{\mathrm{M}}{ }^{\mathrm{a}} \mathrm{NS}$ & $K_{\mathrm{H}}$ & $K_{\mathrm{M}}$ & \\
\hline $\mathrm{Zn}$ & 8.38 & 1.58 & 2.66 & 0.94 & 7.81 & 8.68 & 0.27 & 0.76 & 9.05 & 2.27 & 7.11 & 0.70 & 7.95 & 8.41 & 5.84 & 0.51 \\
\hline $\mathrm{Cu}$ & 10.9 & 1.04 & 9.37 & 0.70 & 15.1 & 7.39 & 13.8 & 0.62 & 11.92 & 11.09 & 1.00 & 0.61 & 16.08 & 15.34 & 6.80 & 0.22 \\
\hline $\mathrm{Ni}$ & 7.75 & 1.68 & 0.98 & 0.75 & 13.1 & 7.04 & 12.3 & 0.60 & 7.14 & 0.12 & 1.01 & 0.85 & 13.2 & 1.00 & 13.0 & 0.50 \\
\hline $\mathrm{Pb}$ & 11.0 & 0.98 & 4.00 & 0.81 & 8.85 & 8.14 & 0.93 & 0.41 & 9.67 & 5.52 & 5.00 & 0.75 & 11.9 & 1.82 & 12.4 & 0.31 \\
\hline $\mathrm{Cd}$ & 8.63 & 1.00 & 6.63 & 0.91 & 8.62 & 6.66 & 6.87 & 0.71 & 8.45 & 0.69 & 7.41 & 0.88 & 7.91 & 1.00 & 6.83 & 0.75 \\
\hline
\end{tabular}

The values of $R^{2}>0.18$ are significant at $5 \%$ probability level

${ }^{a}$ As estimated by WHAM VII-Model II

${ }^{\mathrm{b}}$ As estimated by Baker soil test-Model III 
risk assessment was carried out, i.e. only metal intake by consumption of palatable portion of spinach and wheat was considered. Being a staple food, wheat constitutes the major portion of the diet in India, whereas the proportion of spinach in the diet is small. Considering this fact, the upper safe limits of HQ for staple food (wheat) and green leafy vegetables (spinach) have been fixed at 0.50 and 0.25 , respectively. The values of HQ as calculated for spinach ranged from 0.006 to 0.790 for $\mathrm{Ni}, 0.027$ to 5.492 for $\mathrm{Pb}$ and $0.035-11.32$ for $\mathrm{Cd}$ (Table 3). The values of HQ in respect of Ni were less than 0.25 except for Sonepat soils (Soil No. 26). Debari and Sonepat soils showed high values of $\mathrm{HQ}$ for $\mathrm{Pb}$ and $\mathrm{Cd}$, thereby indicating that leafy vegetables raised on these soils may not be suitable

Table 3 Hazard quotient (HQ) of spinach grown in experimental soils based on actual (measured) metal content in plant

\begin{tabular}{|c|c|c|c|c|}
\hline Soil No & Location & $\mathrm{Ni}$ & $\mathrm{Pb}$ & $\mathrm{Cd}$ \\
\hline 1 & \multirow{9}{*}{$\begin{array}{l}\text { Debari, Udaipur, } \\
\text { Rajasthan }\end{array}$} & 0.054 & 2.101 & 11.32 \\
\hline 2 & & 0.016 & 0.303 & 0.991 \\
\hline 3 & & 0.037 & 1.848 & 8.067 \\
\hline 4 & & 0.011 & 0.315 & 0.847 \\
\hline 5 & & 0.012 & 0.163 & 0.435 \\
\hline 6 & & 0.012 & 0.165 & 1.107 \\
\hline 7 & & 0.022 & 0.123 & 0.492 \\
\hline 8 & & 0.013 & 0.092 & 0.059 \\
\hline 9 & & 0.012 & 0.785 & 8.018 \\
\hline 10 & \multirow[t]{7}{*}{ Keshopur, Delhi } & 0.019 & 0.132 & 0.082 \\
\hline 11 & & 0.008 & 0.130 & 0.092 \\
\hline 12 & & 0.012 & 0.114 & 0.077 \\
\hline 13 & & 0.181 & 0.101 & 0.173 \\
\hline 14 & & 0.011 & 0.129 & 0.077 \\
\hline 15 & & 0.011 & 0.157 & 0.138 \\
\hline 16 & & 0.011 & 0.136 & 0.068 \\
\hline 17 & \multirow[t]{3}{*}{ Madanpur, Delhi } & 0.011 & 0.111 & 0.058 \\
\hline 18 & & 0.009 & 0.129 & 0.086 \\
\hline 19 & & 0.010 & 0.117 & 0.093 \\
\hline 20 & \multirow[t]{2}{*}{ IARI farm, New Delhi } & 0.009 & 0.104 & 0.044 \\
\hline 21 & & 0.008 & 0.100 & 0.065 \\
\hline 22 & \multirow{3}{*}{$\begin{array}{l}\text { Dhapa, Kolkata, West } \\
\text { Bengal }\end{array}$} & 0.012 & 3.469 & 0.097 \\
\hline 23 & & 0.013 & 5.492 & 0.182 \\
\hline 24 & & 0.012 & 2.830 & 0.113 \\
\hline 25 & \multirow[t]{4}{*}{ Sonepat, Haryana } & 0.084 & 0.069 & 0.521 \\
\hline 26 & & 0.790 & 0.102 & 0.114 \\
\hline 27 & & 0.094 & 0.087 & 0.247 \\
\hline 28 & & 0.147 & 0.066 & 0.101 \\
\hline 29 & \multirow[t]{5}{*}{ RAU, Bihar } & 0.006 & 0.027 & 0.035 \\
\hline Minimum & & 0.006 & 0.027 & 0.035 \\
\hline Maximum & & 0.790 & 5.492 & 11.32 \\
\hline Mean & & 0.057 & 0.672 & 1.165 \\
\hline Standard Deviation & & 0.145 & 1.260 & 2.767 \\
\hline
\end{tabular}

for human intake. The HQ values of $\mathrm{Pb}$ exceeded the safe limit of 0.25 for spinach grown on Dhapa soil. The HQ values in connection with the consumption of wheat grain are presented in Table 4. Average values of $\mathrm{HQ}$ for $\mathrm{Ni}, \mathrm{Pb}$ and $\mathrm{Cd}$ were $0.22,0.44$ and 5.97, respectively. For Ni, the HQ values were lower than 0.50 in all the studied soils except Sonepat soil (all soil samples from Sonepat) and Keshopur soil (Soil No. 13). Higher HQ for Cd in twenty four soil samples indicates that wheat crop raised on these soils is not suitable for human intake. There is strongest evidence that $\mathrm{Zn}$ is required for immune- support of human being (Gombart et al. 2020). Zinc is also required to check the incidence of respiratory tract infection, pneumonia and diarrhea, thereby increasing the immunity in

Table 4 Hazard quotient (HQ) of wheat grain grown in experimental soils based on actual (measured) metal content in plant

\begin{tabular}{|c|c|c|c|c|}
\hline Soil No & & $\mathrm{Ni}$ & $\mathrm{Pb}$ & $\mathrm{Cd}$ \\
\hline 1 & Debari, Udaipur, Rajasthan & 0.28 & 0.46 & 59.5 \\
\hline 2 & & 0.05 & 0.42 & 3.71 \\
\hline 3 & & 0.10 & 0.39 & 39.1 \\
\hline 4 & & 0.14 & 0.37 & 2.26 \\
\hline 5 & & 0.08 & 0.59 & 2.85 \\
\hline 6 & & 0.11 & 0.36 & 5.04 \\
\hline 7 & & 0.06 & 0.28 & 2.17 \\
\hline 8 & & 0.17 & 0.16 & 0.33 \\
\hline 9 & & 0.16 & 0.62 & 38.5 \\
\hline 10 & Keshopur, Delhi & 0.44 & 0.58 & 0.51 \\
\hline 11 & & 0.11 & 0.16 & 0.65 \\
\hline 12 & & 0.16 & 0.33 & 0.82 \\
\hline 13 & & 0.64 & 0.80 & 1.24 \\
\hline 14 & & 0.11 & 0.34 & 0.69 \\
\hline 15 & & 0.11 & 0.35 & 0.96 \\
\hline 16 & & 0.08 & 0.17 & 0.69 \\
\hline 17 & Madanpur, Delhi & 0.06 & 0.27 & 0.46 \\
\hline 18 & & 0.05 & 0.23 & 0.71 \\
\hline 19 & & 0.07 & 0.28 & 0.51 \\
\hline 20 & IARI farm, New Delhi & 0.05 & 0.13 & 0.10 \\
\hline 21 & & 0.07 & 0.48 & 0.24 \\
\hline 22 & Dhapa, Kolkata, West Bengal & 0.09 & 0.43 & 0.82 \\
\hline 23 & & 0.39 & 1.21 & 0.97 \\
\hline 24 & & 0.10 & 1.12 & 1.35 \\
\hline 25 & Sonepat, Haryana & 0.64 & 1.16 & 2.17 \\
\hline 26 & & 0.47 & 0.28 & 2.98 \\
\hline 27 & & 0.80 & 0.28 & 2.51 \\
\hline 28 & & 0.76 & 0.26 & 1.07 \\
\hline 29 & RAU, Bihar & 0.05 & 0.13 & 0.17 \\
\hline Minimum & & 0.05 & 0.13 & 0.10 \\
\hline Maximum & & 0.80 & 1.21 & 59.5 \\
\hline Mean & & 0.22 & 0.44 & 5.97 \\
\hline Standard Deviation & & 0.23 & 0.29 & 13.9 \\
\hline
\end{tabular}


human beings. Hence, we can infer that adequate intake of $\mathrm{Zn}$ by human may be helpful in combating the pandemic situation like outbreak of COVID 19. Recommended dietary allowances for human are $2-11 \mathrm{mg}$ for infants and children, $11 \mathrm{mg}$ for adult men, $8 \mathrm{mg}$ for adult women and 11-13 mg for pregnant women and lactating mother (Institute of Medicine 2001). On an average, more than $30 \%$ of the world's citizens is affected by $\mathrm{Zn}$ deficiency with the range of 4-73\% in different countries throughout the globe. The $\mathrm{Zn}$ deficiency is prime causative ingredient for the growth of diseases and illness in the world as well as developing nations (WHO 2002). Zinc enrichment in wheat grain grown on contaminated soil can be regarded as one of the beneficial facets of solid waste and waste water irrigation provided that the content of hazardous element (e.g. $\mathrm{Ni}, \mathrm{Pb}$ and $\mathrm{Cd}$ ) in the palatable portion of crop is within safe limit $(\mathrm{HQ}<0.5)$. For example, daily ingestion of $\mathrm{Zn}$ by consuming $200 \mathrm{~g}$ wheat grain raised on tube well irrigated IARI soil is $3.75 \mathrm{mg}$ (Soil No. 20), whereas $8.54 \mathrm{mg}$ of $\mathrm{Zn}$ could be supplemented through daily dietary intake of wheat grain grown on domestic sewage irrigated soil (Soil No. 21). Figure 2 shows that values of $\left(\mathrm{M}^{2+}\right)$ and $\mathrm{M}_{\text {spinach }}$ were either, respectively, (i) both calculated, (ii) calculated and predicted through solubility and FIAM (iii) calculated and predicted through the FIAM. There was reasonable agreement among all the four plots (Fig. 1), which may explain the utility of soil chemical properties, namely soil $\mathrm{pH}$, organic carbon and extractable metal to measure risk from edibles consumption.

\section{Permissible limits}

Permissible limits for soil metal concentrations were also ascertained on the basis of predicted HQ using the plant metal content modelled by model II i.e. FIAM based on measured free ion activity involving Rhizon-WHAM, for intake of $\mathrm{Cd}$ in humans due to consumption of spinach and wheat grain (Figs. 3, 4). The level of extractable Cd in soil corresponding to the $\mathrm{HQ}>0.25$ for Cd intake via consumption of spinach grown thereon was considered as the permissible limit. The DTPA-extractable Cd in soil corresponding to the HQ $>0.50$ was considered as safe limit for wheat crop. Figure 2 shows that the safe limit of DTPA-extractable $\mathrm{Cd}$ in soil will be $0.05 \mathrm{mg} \mathrm{kg}^{-1}$ for spinach at $\mathrm{pH}$ of 6 and organic carbon content of $0.25 \%$; the corresponding safe limit of Cd will be $0.30 \mathrm{mg} \mathrm{kg}^{-1}$ at $\mathrm{pH}$ of 8.0 and organic carbon of $0.5 \%$. Similarly, the safe limit of DTPA-extractable Cd in soil will be $0.03 \mathrm{mg} \mathrm{kg}^{-1}$ for wheat at $\mathrm{pH} 6.0$ with $0.25 \%$ organic carbon; the corresponding safe limit of $\mathrm{Cd}$ will be $0.11 \mathrm{mg} \mathrm{kg}^{-1}$, if $\mathrm{pH}$ and organic carbon remains at 8.0 and $0.5 \%$, respectively (Fig. 3). It is evident that HQ with respect to $\mathrm{Cd}$ for spinach and wheat grown in the experimental soils exceeded in several cases. A ready reckoner was generated for calculating crop specific safe level of extractable $\mathrm{Cd}$ in soil in connection with human health hazard. In the experimental soil, the safe level of extractable $\mathrm{Cd}$ in soil ranged broadly with the variation in soil organic carbon, while such variation was not noted with soil $\mathrm{pH}$. This can be ascribed to the narrow scale of $\mathrm{pH}$ (alkaline $\mathrm{pH}$ scale) of the experimental soils. Such research findings have practical implication for fixing the safe limit of extractable metal considering

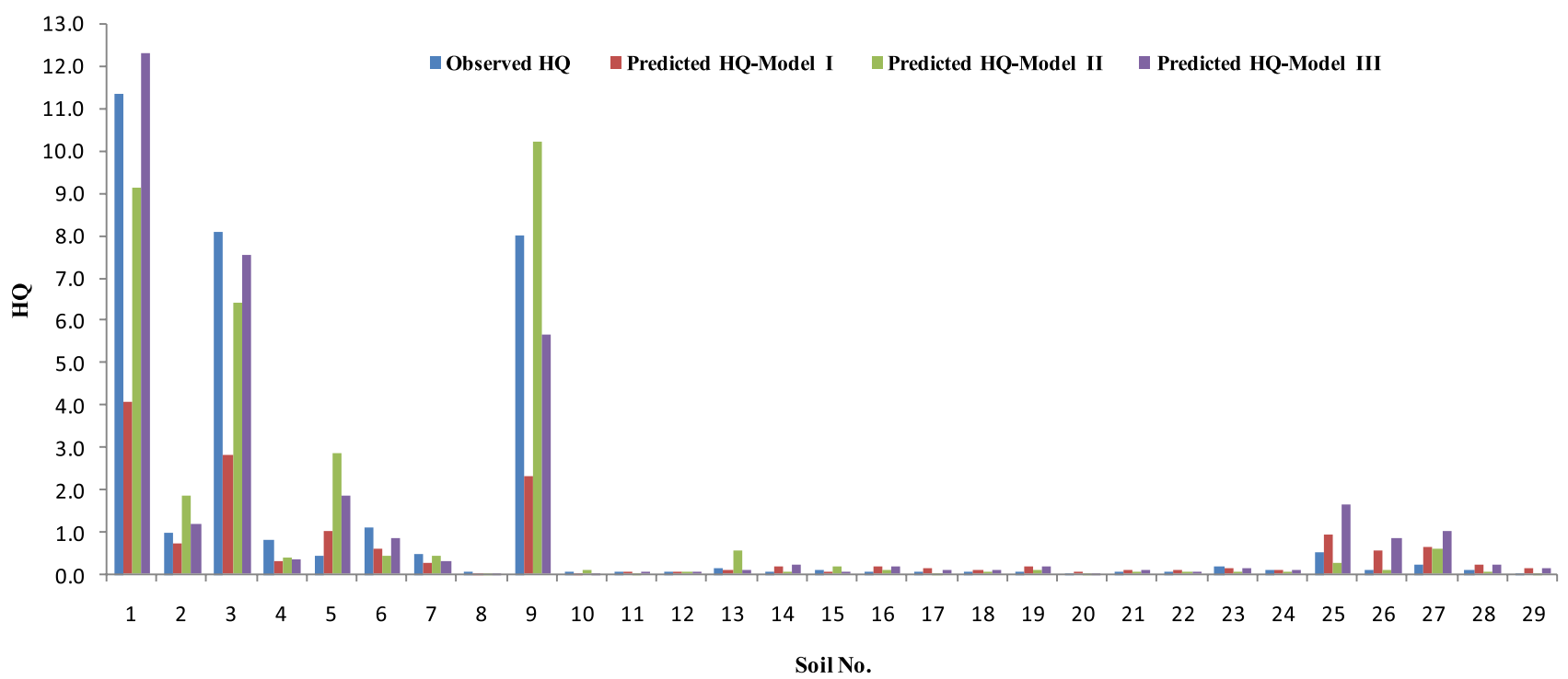

Fig. 2 Comparison of observed and predicted hazard quotients for $\mathrm{Cd}$ in spinach; prediction was made from the free ion activity model using values of $\left(\mathrm{Cd}^{2+}\right)$ ions either from speciation of the extracted pore water or using the generic solubility model 


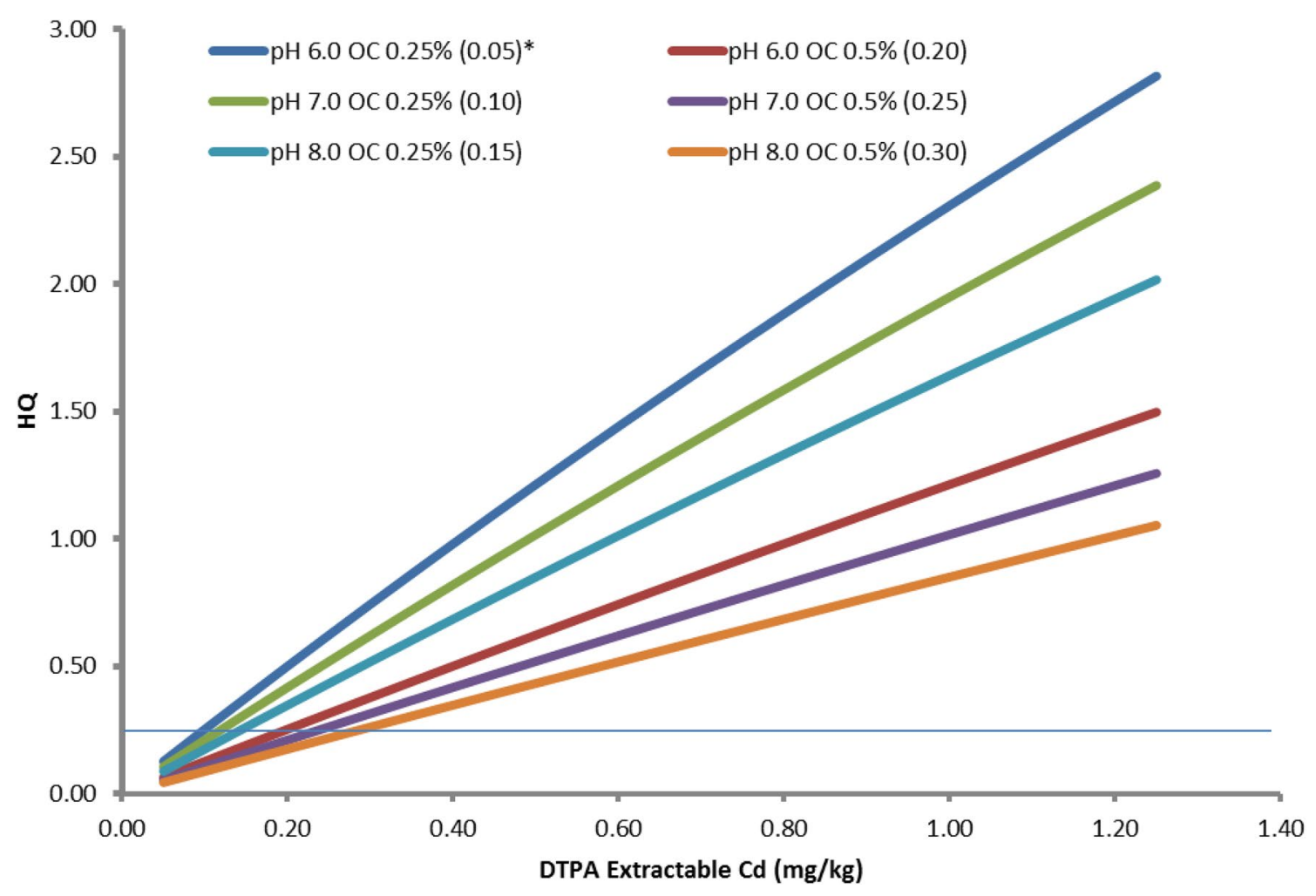

Fig. 3 Permissible limit of DTPA extractable Cd in soils in relation to solubility of metal for intake of Cd through spinach by human. *Values in parentheses indicate the toxic limit of extractable $\mathrm{Cd}$ in soil

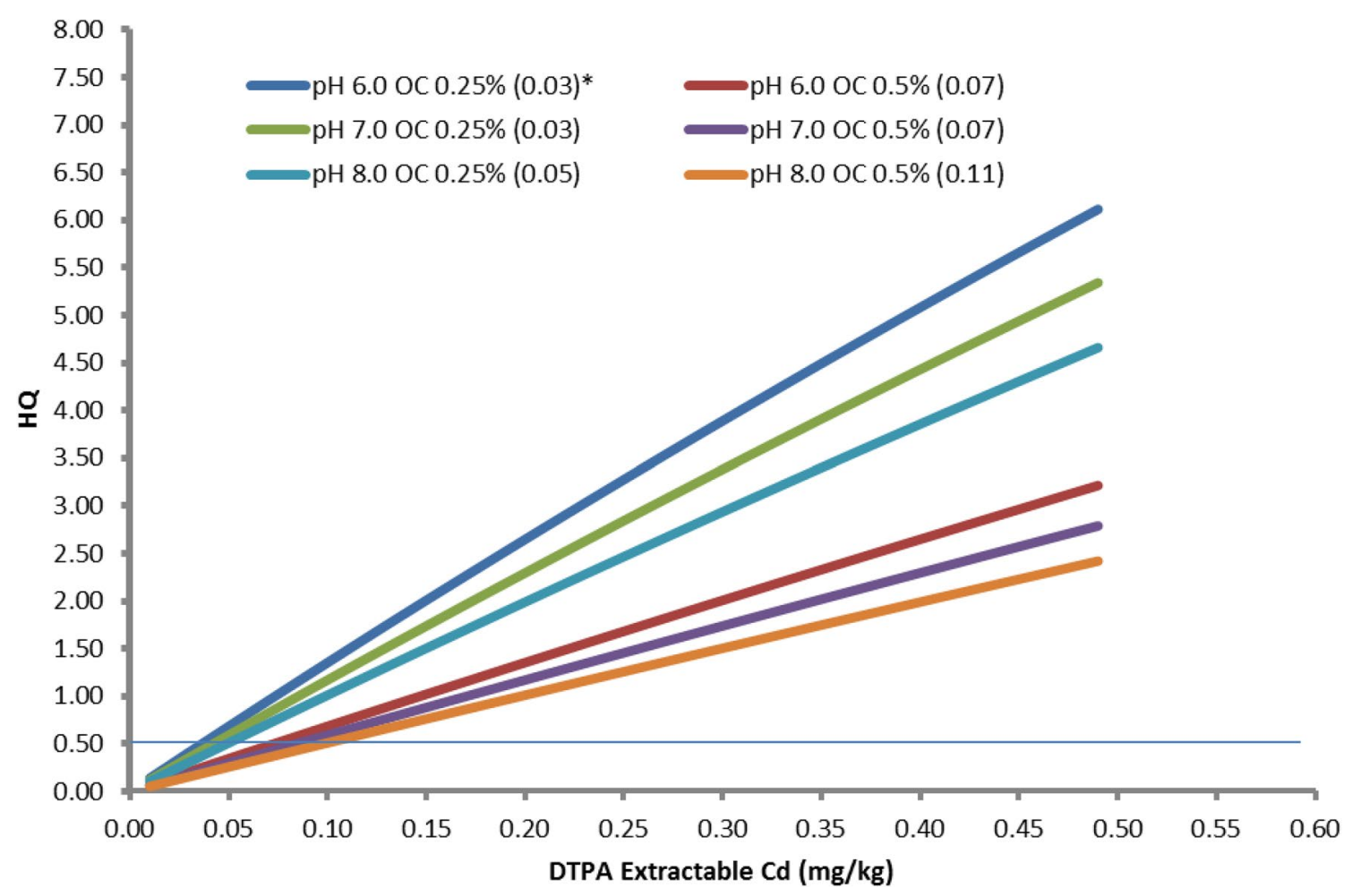

Fig. 4 Permissible limit of DTPA extractable Cd in soils in relation to solubility of metal for intake of Cd through wheat grain by human. *Values in parentheses indicate the toxic limit of extractable $\mathrm{Cd}$ in soil 
the important soil properties, since total metal content is not a good metal hazard index to human health vis-à-vis phytoavailability.

\section{Conclusions}

The novelty of this study is a comparative evaluation of efficacy of different formulations of FIAM in predicting the metal uptake by crops. Furthermore, prescription of safe level of metal in soils in connection with health hazard of human for intake of metal by food materials is a new concept, and should constitute priority area of research in the field of metal pollution. There is also scarcity of free metal ion activity data as speciated through most recent and robust speciation model, WHAM VII. The FIAM, based on measured free ion activity of metals in soil solution extracted by Rhizon sampler, was distinctly superior to other formulations in predicting the metal uptake by spinach and wheat. The efficacy of Model I was more or less at par in predicting the metal uptake by plants. The protocol used in the present investigation for assessing the safe level of extractable metal may be practical for the appraisal of risk related to contaminated soils on routine basis, as well as in devising the management options for specific contaminated sites. We expect that this novel approach of risk assessment will prove to be useful and promising.

Supplementary Information The online version contains supplementary material available at https://doi.org/10.1007/s12665-021-09988-7.

Author contributions DG: Conceptualization, Methodology, Data curation, Formal analysis, Visualization, Writing-original draft, Investigation. SPD: Supervision, Resources, Validation, Writingreview and editing. BSD: Visualization, Formal analysis and editing. MCM: Data curation, Formal analysis and editing. PR: Review and editing. VKT: Formal analysis, review and editing.

Funding Indian Council of Agricultural Research in the form of Senior Research Fellowship.

Availability of data and material Not applicable.

Code availability Not applicable.

\section{Declarations}

Conflict of interest The authors declare that they have no known competing financial interests or personal relationships that could have appeared to influence the work reported in this paper.

Animal research Not applicable.

Consent to participate Not applicable.

Consent to publish Not applicable.

\section{References}

Baker DE, Amacher MC (1981) Development and interpretation of a diagnostic soil testing program. Pennsylvania Agricultural Experiment Station Bulletin No. 826. Pennsylvania Agricultural Experiment Station, University Park, Pennsylvania, 20 pp

Bouyoucos GJ (1962) Hydrometer method improved for making particle size analysis of soils. Agron J 54:464-465

Campbell PGC (1995) Interaction between trace metals and aquatic organisms: a critique of the free-ion activity model. In: Tessier A, Turner DR (eds) Metal speciation and bioavailability in aquatic systems. John Wiley and Sons Ltd, New York, pp 45-102

Cempel M, Nikel G (2006) Nickel, A review of its sources and environmental toxicology. Pol J Environ Stud 15:375-382

Chen YF (2011) Review of the research on heavy metal contamination of China's city soil and its treatment method. China Popul Resour Environ 21:536-539

Chen Y, Wang C, Wang Z (2005) Residues and source identification of persistent organic pollutants in farmland soils irrigated by effluents from biological treatment plants. Environ Int 31:778783. https://doi.org/10.1016/j.envint.2005.05.024

Datta SP, Young SD (2005) Predicting metal uptake and risk to human food chain from leafy vegetables grown on soils amended by long-term application of sewage sludge. Water Air Soil Pollut 163:119-136. https://doi.org/10.1007/s11270-005-0006-6

Deshmukh SK, Singh AK, Datta SP (2015) Impact of wastewater irrigation on the dynamics of metal concentration in the vadose zone: simulation with NETPATH-part II. Environ Monit Assess 187:764. https://doi.org/10.1007/s10661-015-4962-z

Golui D, Guha Mazumder DN, Sanyal SK, Datta SP, Ray P, Patra PK, Sarkar S, Bhattacharya K (2017) Safe limit of arsenic in soil in relation to dietary exposure of arsenicosis patients from Malda district, West Bengal-a case study. Ecotoxicol Environ Saf 144:227-235. https://doi.org/10.1016/j.ecoenv.2017.06.027

Golui D, Datta SP, Dwivedi BS, Meena MC, Trivedi VK (2020) Prediction of free metal ion activity in contaminated soils using WHAM VII, baker soil test and solubility model. Chemosphere 243:125408. https://doi.org/10.1016/j.chemosphere.2019.125408

Gombart AF, Pierre A, Maggini S (2020) A review of micronutrients and the immune system-working in harmony to reduce the risk of infection. Nutrients 12:236. https://doi.org/10.3390/ nu12010236

Groenenberg JE, Romkens PFAM, Comans RNJ, Luster J, Pampura T, Shotbolt L, Tipping E, deVries W (2010) Transfer functions for solid-solution partitioning of cadmium, copper, nickel, lead and zinc in soils: derivation of relationship for free metal ion activities and validation with independent data. Eur J Soil Sci 61:58-73. https://doi.org/10.1111/j.1365-2389.2009.01201.x

Hough RL, Young SD, Crout NMJ (2003) Modelling of Cd, Cu, $\mathrm{Ni}, \mathrm{Pb}$ and $\mathrm{Zn}$ uptake by winter wheat and forage maize from a sewage disposal farm. Soil Use Manag 19:19-27. https://doi. org/10.1111/j.1475-2743.2003.tb00275.x

Hough RL, Young SD, Crout NMJ, Tye AM (2004) Assessing potential risk of heavy metal exposure from consumption of home produced vegetable by urban populations. Environ Health Perspect 112:215-221. https://doi.org/10.1289/ehp.5589

Institute of Medicine (2001) Dietary reference intakes for Vitamin A, Vitamin K, Arsenic, Boron, Chromium, Copper, Iodine, Iron, Manganese, Molybdenum, Nickel, Silicon, Vanadium, and Zinc. National Academies Press, Washington, DC

IRIS (2020) Integrated risk information system database. US Environmental Protection Agency, Washington, DC

Jackson ML (1973) Soil chemical analysis. Prentice Hall of India Private Limited, New Delhi 
Lindsay WL, Norvell WA (1978) Development of a DTPA soil test for zinc, iron, manganese and copper. Soil Sci Soc Am J 42:421-428. https://doi.org/10.2136/sssaj1978.03615995004200030009x

Mandal J, Golui D, Datta SP (2019) Assessing equilibria of organoarsenic complexes and predicting uptake of arsenic by wheat grain from organic matter amended soils. Chemosphere 229:419-426. https://doi.org/10.1016/j.chemosphere.2019.06.088

Mao LC, Young SD, Tye AM, Bailey EH (2017) Predicting trace metal solubility and fractionation in Urban soils from isotopic exchangeability. Environ Pollut 231:1529-1542. https://doi.org/10.1016/j. envpol.2017.09.013

Marzouk ER, Chenery SR, Young SD (2013) Predicting the solubility and lability of $\mathrm{Zn}, \mathrm{Cd}$, and $\mathrm{Pb}$ in soils from a minespoil-contaminated catchment by stable isotopic exchange. Geochim Cosmochim Acta 123:1-16. https://doi.org/10.1016/j.gca.2013.09.004

Meena R, Datta SP, Golui D, Dwivedi BS, Meena MC (2016) Longterm impact of sewageirrigation on soil properties and assessing risk in relation to transfer of metals to humanfood chain. Environ Sci Pollut Res 23:14269-14283. https://doi.org/10.1007/ s11356-016-6556-x

Mishra R, Datta SP, Annapurna K, Meena MC, Dwivedi BS, Golui D, Bandyopadhyay KK (2019) Enhancing the effectiveness of zinc, cadmium and lead phytoextraction in polluted soils by using amendments and microorganisms. Environ Sci Pollut Res 26:17224-17235. https://doi.org/10.1007/s11356-019-05143-9

Nabulo G, Black CR, Young SD (2011) Trace metal uptake by tropical vegetables grown on soil amended with sewage sludge. Environ Pollut 159:368-376. https://doi.org/10.1016/j.envpol.2010.11.007

Oorts K, Ghesquiere U, Swinnen K, Smolders E (2006) Soil properties affecting the toxicity of $\mathrm{CuCl}_{2}$ and $\mathrm{NiCl}_{2}$ for soil microbial processes in freshly spiked soils. Environ Toxicol Chem 25:836-844. https://doi.org/10.1897/04-672R.1

Quevauviller PH (1998) Operationally defined extraction procedures for soil and sediment analysis. Trends Anal Chem 17:289-298. https://doi.org/10.1016/S0165-9936(97)00119-2

Rattan RK, Datta SP, Chhonkar PK, Suribabu K, Singh AK (2005) Long-term impact of irrigation with sewage effluents on heavy metal content in soils, crops and groundwater, a case study. Agric Ecosyst Environ 109:310-322. https://doi.org/10.1016/j.agee. 2005.02.025

Rattan RK, Patel KP, Manjaiah KM, Datta SP (2009) Micronutrients in soil, plant, animal and human health. J Indian Soc Soil Sci 57:546-558
Tipping E, Lofts S, Sonke JE (2011) Humic Ion-Binding Model VII: a revised parameterisation of cation-binding by humic substances. Environ Chem 8:225-235. https://doi.org/10.1071/EN11016

Tye AM, Young SD, Crout NMJ, Zhang H, Preston S, Barbosa-Jefferson VL, Davison W, Mcgrath SP, Paton GI, Kilham K, Resende L (2003) Predicting the activity of $\mathrm{Cd}^{2+}$ and $\mathrm{Zn}^{2+}$ in soil pore water from the radio-labile metal fraction. Geochim Cosmochim Acta 67:375-385. https://doi.org/10.1016/S0016-7037(02)01138-9

USEPA (2017) Sources of lead in soil: a literature review. Battelle Memorial Institute, Washington, DC, p 20460

Vulkan R, Zhao FJ, Barbosa-Jefferson V, Preston S, Paton GI, Tipping E, McGrath SP (2000) Copper speciation and impacts on bacterial biosensors in the pore water of copper-contaminated soils. Environ Sci Technol 34:5115-5121. https://doi.org/10.1021/es000 0910

Walkley A, Black IA (1934) An examination of the degtjareff method for determining soil organic matter, and a proposed modification of the chromic acid titration method. Soil Sci 37:29-38. https:// doi.org/10.1097/00010694-193401000-00003

WHO (2002) The world health report. World Health Organization, Geneva

WHO (1982) Toxicological evaluation of certain food additives, Joint FAO/WHO expert committee on food additives. WHO Food Additive Series No. 683. World Health Organization, Geneva

Zan NR, Datta SP, Rattan RK, Dwivedi BS, Meena MC (2013) Prediction of solubility of zinc, copper, nickel, cadmium and lead in metal contaminated soils. Environ Monit Assess 185:1001510025. https://doi.org/10.1007/s10661-013-3309-x

Zhou H, Yang WT, Zhou X, Liu L, Gu JF, Wang WL, Zou JL, Tian T, Peng PQ, Liao BH (2016) Accumulation of heavy metals in vegetable species planted in contaminated soils and the health risk assessment. Int J Environ Res Public Health 13(3):289. https://doi. org/10.3390/ijerph13030289

Publisher's Note Springer Nature remains neutral with regard to jurisdictional claims in published maps and institutional affiliations. 